\title{
Annual Report:
}

\section{September 2004 to November 2005}

Mary Ellen Jeans, RN, PhD

Secretary General

Association of Canadian Executive Nurses

Because the Annual General Meeting of the Academy of Canadian Executive Nurses (ACEN) was moved to

November from September, this report covers a 14-month period. During this time, ACEN has taken on a new identity on the national front. We have implemented the decisions taken at the last annual meeting related to changes in membership categories and fees, establishing a national office and increasing the Academy's visibility. Membership has been expanded to include nursing executive leaders in healthcare delivery, academia, government and professional associations. The response to this change has been positive, and it is anticipated that membership will continue to increase over the next year. A national office has been established in Ottawa.*

Three standing committees of the Academy have been established. These are: 1) Membership and Governance, 2) Policy and 3) Leadership. The Editorial Advisory Board continues as a fourth committee.

This report addresses ACEN's activities as they relate to the objectives of the Academy.

\section{Objective 1: To Influence and} Participate in Setting the Directions for Healthcare Policy and Dialogue in Canada

Setting up the head office in Ottawa has been key to increasing the visibility of ACEN in the policy environment. Although the secretary general works only six days a month for ACEN, the word has spread quickly that the Academy is in business. ACEN has been invited to participate in numerous meetings and has been consulted on several health policy issues. We attended the Health Human Resources 
Summit, an invitational meeting sponsored by the Health Council of Canada. We are invited to sit on a Nursing Knowledge Network Advisory Group for the Canadian Health Services Research Foundation (CHSRF). The Office of Nursing Policy has invited ACEN to participate in several meetings related to health human resources and interprofessional teamwork. The Canadian Nurses Association has invited ACEN's participation in numerous projects, including the Portal Project, human resources monthly meetings and advanced practice consultations. Several ACEN members attended consultations on the Canadian Nurse Practitioner Initiative that were held across the country. There are also four major national projects in which the Academy is a partner, and one in which we have the lead role. These will be described later in this report.

Considerable time has been dedicated to meeting with other national organizations to introduce ACEN and to maintain effective relationships. Some of the organizations include: Canadian Nurses Association (CNA), Association of Academic Health Organizations (ACAHO), Canadian Healthcare Association (CHA), Canadian Medical Association, Canadian Health Services Research Foundation (CHSRF), Health Canada, Canadian Council of Health Services Accreditation (CCHSA), Canadian Council of Health Services Executives (CCHSE), Canadian Institute of Health Research (CIHR), Canadian Society of Physician Executives and Canadian
Association of Schools of Nursing (CASN). Maintaining this network is key to ensuring ACEN's inclusion in larger initiatives to influence policy. It also ensures that our colleagues learn about and understand ACEN's position on key policy issues.

The major policy priorities continue to be patient safety, nursing workload, health human resources and access to care. ACEN's Policy Committee is in the process of developing a framework for policy analysis in order to determine the Academy's future policy priorities. There has been considerable uptake on patient safety initiatives by members of the Academy. Members of ACEN and ACAHO have attended many national and international initiatives on patient safety and participate in the Safer Healthcare Now campaign. It is clear that patient safety, nursing workload and health human resources are very much interrelated. The health human resources policy arena has been the most active during this year and, given the pending shortage of nurses, it will continue to be a priority for ACEN members. For this reason, the annual conference for 2005 has focused on initiatives related to the 10 recommendations of the Nursing Sector Study. The presentations will be useful as we move ahead with policy formulation for 2006.

Objective 2: To Contribute to the Alignment and Advancement of the National Practice, Education, Research and Leadership Agendas ACEN was represented by Louise Jones at a CNA consultation work- 
shop on advanced nursing practice and a Canadian Nurse Practitioner Initiative (CNPI) workshop on Nurse Practitioner Streams of Practice, October 3-5. Several members of ACEN attended CNPI consultation workshops and roundtables on practice, education, legislation and regulation and health human resources planning that were held across the country in April and May of this year.

ACEN continues to be a partner in the Consortium for the Advancement of Nursing Research and Innovation. A proposal for funding has been developed and is being presented to CIHR and CHSRF. ACEN, along with four other partners (CNA, CASN, Canadian Nurses Foundation and Canadian Association for Nursing Research) of the Consortium, is contributing $\$ 1,000$ to develop an annual award for nursing research that will be administered by CIHR. This will be an annual commitment for the next three to five years.

The Academy has been invited to join other health research organizations. We have deferred doing so until we have a better idea of our potential budget and the time commitment of a part-time secretary general.

ACEN has provided letters of support to two major research projects with multidisciplinary teams led by nurse researchers. The first was for Dr. Nancy Edwards from the University of Ottawa. The second letter was sent in support of a proposal led by Dr. Judith Watt-Watson from the University of Toronto. ACEN continues to support education and research as key to highquality patient care. Evidence-based practice and policies constitute the cornerstones of effective healthcare delivery.

\section{Objective 3: To Develop Strong Strategic Coalitions and Partnerships with Other Healthcare Leadership Groups}

ACEN meets on a regular basis with other national organizations. In addition, the Academy is a partner on four major projects, one of which has already been mentioned: the Consortium for Nursing Research and Innovation. The other three include:

\section{Development of healthcare leaders and managers in Canada}

This project is the product of at least two years of discussions and several meetings and consultations with stakeholders. It is led by CCHSE, ACEN and Canadian Association of Physicians for the Environment. The first phase of the project was funded by the health sector division of Human Resources Skills Development Canada (HRSDC). The purpose of the project is to identify the characteristics of the current cohort of health leaders and describe challenges and issues related to health leadership, including recruitment and retention issues, among others. A proposal has been developed to move into the next phase, which will be an extensive research initiative. The proposal is being vetted by a subcommittee of the federal, provincial and territorial Advisory Committee on Health Delivery and Human Resources. Funding, if approved, will come from HRSDC's health sector division and 
will focus on human resources planning for health leaders and managers. This project will take at least two years to complete and could be followed by an implementation phase. ACEN is represented on the management committee by Patricia O'Connor and Mary Ellen Jeans. The secretariat for this project is located with CCHSE, and Mary Ellen Jeans works with the staff to prepare several of the written documents related to the project.

\section{Quality Worklife-Quality Healthcare Collaborative}

This project involves the collaboration of 11 national health system partners whose working principle is "leadership with shared ownership." The QWQHC aims to improve quality of worklife for healthcare organizations by formulating strategies to address a broad range of health human resources challenges and to improve healthcare delivery and patient outcomes.

The Collaborative will promote the following long-term objectives within Canadian healthcare organizations:

- creating and maintaining healthy, safe, supportive and positive work environments;

- building leadership, with a commitment for action on excellence in "people practices";

- developing healthcare employees and professional staff who are highly skilled, engaged and satisfied; and

- making a strategic link between high-quality, healthy work environments and healthcare organizational effectiveness (including high-quality patient care and patient safety).

The secretariat for this Collaborative is CCHSA. Wendy Hill, incoming ACEN president, is a member of the project steering committee, and Mary Ellen Jeans is a member of the partners group, which supports the steering committee and implements directions for the project.

\section{Healthcare leadership challenges for interprofessional practice}

ACEN submitted a proposal to the Office of Nursing Policy under the health human resources initiative to

- publish a series of human resource papers and reports through our journal in collaboration with Longwoods Publishing and

- host an invitational meeting for health leaders in healthcare delivery, professional regulation, education and professional associations to identify issues and challenges in promoting and supporting interprofessional practice.

The invitational meeting will take place in Ottawa on February 24 and 25,2006 . A background paper will be prepared in advance of the meeting. There will be a concerted effort to generate some action-oriented recommendations, and the meeting attendees will be in a position to influence implementation. ACEN will seek partners in this initiative over the next few weeks.

\section{Nursing Leadership Conference} On February 20, 2005, ACEN partnered once again with CNA, CHA, CASN, 
CCHSE and Canadian Public Health Association to host the biennial leadership conference. At the conference, ACEN hosted a reception that was supported by Johnson \& Johnson. It was a great success. ACEN president Barb McGill gave a presentation on ACEN's new membership categories, directions for the future and the establishment of a national office. We have already committed to participate in the 2007 leadership conference.

\section{Objective 4: To Support the Development of Current and} Emerging Executive Nurse Leaders in Canada

ACEN's newly established Leadership Committee is currently planning a leadership agenda and will make a presentation at the Annual General Meeting in November. Ideas include a substantial mentorship program and skills development workshops. Committee members will consult with other ACEN members to determine priorities for leadership development.

ACEN continues to support leadership development through its scholarship program. This year the scholarship was awarded to Marie-Claire Richer, a $\mathrm{PhD}$ candidate in nursing at McGill University.

ACEN will continue to explore partnerships and opportunities to promote leadership development for nurses. There are several initiatives in which ACEN members continue to be involved, such as the CHSRF Extra Program.
Finally, the Canadian Journal of Nursing Leadership, as the official journal of ACEN, remains our foremost leadership product. It continues to grow in distribution. We are also pleased to continue to work with the publisher, Longwoods, to explore new and creative ways to promote nursing leadership.

\section{Objective 5: To Provide a Forum to Discuss and Share Ideas Related to Nursing Practice, Education, Research and Leadership}

It is ACEN's intent to create an intellectual space for all Canadian nursing executives. The challenges facing healthcare and nursing can no longer be addressed by one professional nursing group alone. That is why ACEN has expanded its membership to include nurse executives in academia, professional associations and government. We have an opportunity now to work strategically together in the interests of our profession and of all Canadians. If you have colleagues who have not yet joined ACEN, please encourage them to do so. The greater our number, the greater our influence.

Our journal, of course, remains our formal venue for dialogue. However, on a day-to-day basis, the listserve and the newly configured ACEN website, www. acen.ca, provide opportunities for less formal discussion. The ACEN executive meets at least once each month by teleconference and in person from time to time, usually at meetings or conferences. This contact keeps ACEN abreast of emerging issues across the country. 


\section{Objective 6: To Support the Editor and Editorial Advisory Board in Providing the Canadian Journal of Nursing Leadership}

As suggested earlier, CJNL is the main branding for ACEN and, as such, must represent excellence. To date, we are very pleased with the quality of the journal and anticipate its continued growth in circulation. The editor, Dr. Dorothy Pringle, and the Editorial Advisory Board chair, Dr. Mary Ferguson-Paré, are to be congratulated. Special thanks go to Anton Hart, the publisher, and the Longwoods team.

Be assured that ACEN is in good health and is growing. It continues to pursue four primary goals:
- to become a national voice for executive nurse leaders;

- to influence and participate in direction setting for healthcare policy;

- to contribute to the advancement of the national nursing agenda; and

- to develop strong strategic partnerships and alliances.

Our effectiveness comes from our collective knowledge, spheres of influence and strategic thinking.

\section{ACEN is pleased to announce the 2005 recipient of the ACEN}

\section{Scholarship - Marie-Claire Richer}

Mlle. Richer is a PhD candidate in the School of Nursing, McGill University. Her professional experience has ranged from working "on the front line" in an emergency department and intensive care unit, to teaching nursing at both the college and university level. She has held management and clinical leadership positions as director of an educational program in the private sector and as a CNS in women's health. As she states, "throughout my varied positions and educational programs at the CEGEP St. Laurent, my undergraduate studies at the University of Montreal and graduate education at McGill University, I had the opportunity to reflect on the role that nurses hold in creating and sustaining the conditions for excellence in our healthcare system". During her doctoral studies at McGill and as part of the first cohort in the FERASI program, Ms. Richer pursued this interest further. Her doctoral study will explore the effect of Appreciative Inquiry on the development of innovative ideas surrounding the organization of care delivery. Of particular interest to her is the potential of this method to influence work satisfaction and retention. Ms. Richer notes that results of this study will offer a new approach to nurses collaborating with other healthcare professionals in innovative planning. 